\title{
Fauna prizemnih člankonožaca (Arthropoda) u nasadu smokve (Ficus carica L.)
}

\author{
Fauna of epigeic arthropods (Arthropoda) in common fig orchard \\ (Ficus carica L.)
}

\author{
K. Franin, M. Ražnjević, Š. Marcelić, Branka Maričić, T. Kos
}

\section{SAŽETAK}

Smokva (Ficus carica L.) je mediteranska voćna kultura koja ima dugu tradiciju uzgoja na području Ravnih kotara. Područje istraživanja se nalazilo u blizini mjesta Polača u nasadu smokve $\mathrm{s}$ integriranim sustavom proizvodnje. Zastupljene sorte su „Zamorčica“, „Bjelica“ i „Petrovača bijela“. Način gospodarenja tlom u voćnjacima igra važnu ulogu u aktivnosti i raznolikosti faune prizemnih člankonožaca. Istraživanje je provedeno s ciljem proučavanja sastava i aktivnosti faune prizemnih člankonožaca $u$ zakorovljenom za razliku od pokošenog i malčiranog nasada smokve. Za vrijeme pokusa nasad smokve je bio podijeljen na dva dijela. Jedan dio bio je zakorovljen, a drugi pokošen i malčiran nekoliko puta tijekom vegetacijske sezone. Istraživanje je trajalo od svibnja do rujna 2017. Uzorkovanje je obavljeno korištenjem lovnih posuda (,pitfall traps“). Ulovljeno je sveukupno 1689 jedinki koje pripadaju u 2 razreda, 7 redova i 15 porodica. Na zatravljenom dijelu pronađeno je 993 jedinki, dok je na pokošenom zabilježeno 696 jedinki. Najbrojniji su bili: opnokrilci (Hymenoptera - por. Formicidae), kornjaši (Coleoptera) i pauci (Araneae). U ovom istraživanju dominirali su mravi sa zastupljenošću od 77. 68\% ukupnog ulova.

Ključne riječi: integrirana proizvodnja, kukci, mravi, smokva

\begin{abstract}
The common fig tree (Ficus carica L.) is a Mediterranean fruit species that has a long tradition of cultivation in Ravni kotari (Croatia). The study area was located near the Polača in the common fig orchard under an integrated system of growing. Presented varieties are „Zamorčica“, „Bjelica“, and „Petrovača bijela“. Orchard floor management plays an important role in the epigeic arthropods fauna activity and diversity. This study aims at investigating the assemblage and activity of arthropods in weedy, unlike the mowed and mulched fig orchard. During this research, fig orchard was divided into two parts. One covered with weeds, whereas the other one mowed and mulched several times through the vegetational season. This research was performed from May until September 2017. Epigeic arthropod fauna was sampled using pitfall traps. In this
\end{abstract}


K. Franin i sur.: Fauna prizemnih člankonožaca (Arthropoda) u nasadu smokve (Ficus carica L.)

research, a total of 1689 specimens belonging to 2 classes, 7 orders and, 15 families were captured. In the weedy part of the orchard, 993 individuals were found, unlike the mowed and mulched where 696 individuals were noticed. The most abundant were Hymenoptera (fam. Formicidae) followed by Coleoptera and Araneae. In this research, ants dominated with $77.68 \%$ of total capture.

Key words: ants, common fig, insects, integrated growing

\section{UVOD}

Smokvu na cijelom uzgojnom području napada velik broj štetnika koji su zonalno raspodijeljeni zbog posebnosti pojedinih klimatskih područja. $\mathrm{Na}$ našem području uzgoja smokve pojavljuje se veliki broj polifagnih štetnika, međutim veće štete nastaju napadom monofagnih vrsta koje su zastupljene $u$ manjem broju (Bakarić i sur., 1989.). Među najvažnije štetnike smokve ubrajaju se smokvina buha (Homotoma ficus L.) koja napada list smokve hraneći se sokom i smokvin medić (Ceroplastes rusci L.). Od ostalih štetnih vrsta pojavljuju se: mali smokvin potkornjak (Hypoborus ficus Erich.) koji napada zakržljale ili suhe grane, smokvin moljac (Simaethis nemorana Hb.), te zlatna mara (Cetonia aurata L.) koja uzrokuje štete na zrelim plodovima (Maceljski, 2002.). U novije vrijeme mediteranska voćna muha (Ceratitis capitata Wied.) uzrokuje sve veće štete na područjima gdje se uzgaja smokva (Alonso-Mũnoz i Marí, 2011., Bulić i sur., 2012., Gonçalves, 2017.). Od korisnih vrsta za uzgoj određenih sorti smokve neophodna je osica (Blastophaga psenes L.) koja obavlja kaprifikaciju i omogućuje oplodnju (Bakarić i sur., 1989.). Ova osica je posebno značajna za kultivare kao što su „Smirna“ i „Petrovača bijela“, dok je kod jednorotke „Zamorčice“ nepotrebna (Prgomet, 2003.). Bain i sur. (2015.) spominju 27 vrsta osica u fauni smokve. Fauna člankonožaca povezanih sa smokvom i općenito rodom Ficus je u Hrvatskoj, a posebno na području Ravnih kotara nedovoljno istražena, dok je dostupna literatura o toj temi vrlo oskudna. Mifsud i sur. (2012.) navode 39 vrsta člankonožaca na različitim vrstama roda Ficus na području Malte, od kojih je 33 štetno, dok su ostale prarazitoidi ili predatori. Fauna prizemnih člankonožaca u nasadima smokve je također slabo istražena. Merlim i sur. (2005.) u istraživanju faune tla u organskom uzgoju smokve navode da mravi čine $80 \%$ cjelokupne faune tla, a od ostale faune zastupljeni su pauci (Aranea), strige (Chilopoda) i maločetinaši (Oligochaeta). Nait-Kaci i sur. (2014.) u istraživanju makrofaune tla u nasadima smokve na području Alžira zaključuju da mravi čine 70 \% faune člankonožaca. U Indiji Singh i Kaur (2017.) pronalaze sveukupno 17 vrsta člankonožaca od kojih je 14 štetno. Među štetnicima autori posebno navode nekoliko vrsta roda Bactrocera, 
K. Franin i sur.: Fauna prizemnih člankonožaca (Arthropoda) u nasadu smokve (Ficus carica L.)

a od korisnih osicu Blastophga. Osnovni cilj ovog istraživanja bio je utvrditi faunu prizemnih člankonožaca u zatravljenom i pokošenom (malčiranom) nasadu smokve na području Ravnih kotara.

\section{MATERIJALI I METODE}

Istraživanje je provedeno na području Ravnih kotara u mjestu Polača. Prema Köppen-ovoj klasifikaciji, ovo područje pripada submediteranskoj klimatskoj zoni (Cfa), koju karakteriziraju vruća ljeta (Penzar i Penzar, 1989.). Nasad je podignut 2002. Tlo je smeđe na vapnencu. Površina voćnjaka koja iznosi 1 ha je zatravljena, prepuštena samonikloj korovnoj flori, a održava se košnjom. Sustav navodnjavanja je po modelu „kap na kap“. Prevladava sorta „Zamorčica“, a uz nju su još prisutne „Petrovača bijela“ i „Bjelica“. Razmak sadnje iznosi 6 x 6 m, a uzgojni oblik je vaza. Istraživanje je trajalo od svibnja do kolovoza 2017. godine. Prilikom istraživanja nasad je podijeljen na dva dijela: jedan je bio zapušten, odnosno zarastao u korov, a drugi održavan košnjom koja je provođena svakih 7 dana. Za uzorkovanje faune tla korištene su lovne posude „pitfall traps“. Posude su visine $18 \mathrm{~cm}$ i promjera $11 \mathrm{~cm}$. Postavljeno je sveukupno 10 posuda, pet na zakorovljenom i pet na pokošenom dijelu voćnjaka. Uzorkovanje je provedeno 3 puta mjesečno. U svaku posudu stavljena je mješavina vode $\mathrm{i}$ etanola u omjeru $3: 1$, te je dodano $5 \mathrm{~g} \mathrm{NaCl}$ i nekoliko kapi detergenta radi smanjivanja površinske napetosti. Posude su ostavljene u polju $48 \mathrm{~h}$ nakon postavljanja, a uzorci su zatim prikupljeni i pohranjeni u 70\%-tnom etanolu. Determinacija je obavljena do razine reda, a gdje je bilo moguće i do porodice korištenjem entomoloških ključeva (Schmidt, 1970.).

\section{REZULTATI I RASPRAVA}

Tijekom ovog istraživanja ulovljeno je sveukupno 1689 jedinki iz dva razreda i sedam redova (Slika 1.). Od toga je 993 jedinki pronađeno u zakorovljenom (Slika 2.), a 696 u pokošenom i malčiranom dijelu voćnjaka (Slika 3.). 
K. Franin i sur.: Fauna prizemnih člankonožaca (Arthropoda) u nasadu smokve (Ficus carica $\mathrm{L}$.)

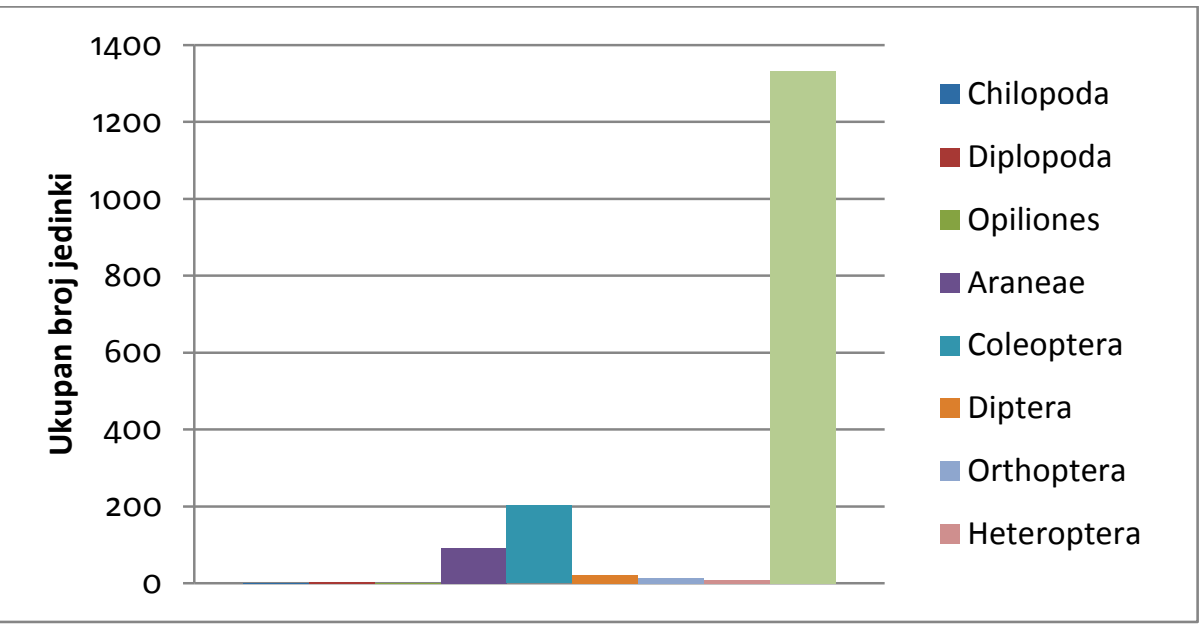

Slika 1. Ukupan broj jedinki člankonožaca u nasadu smokve

Figure 1 Total number of arthropod specimens in the common fig orchard

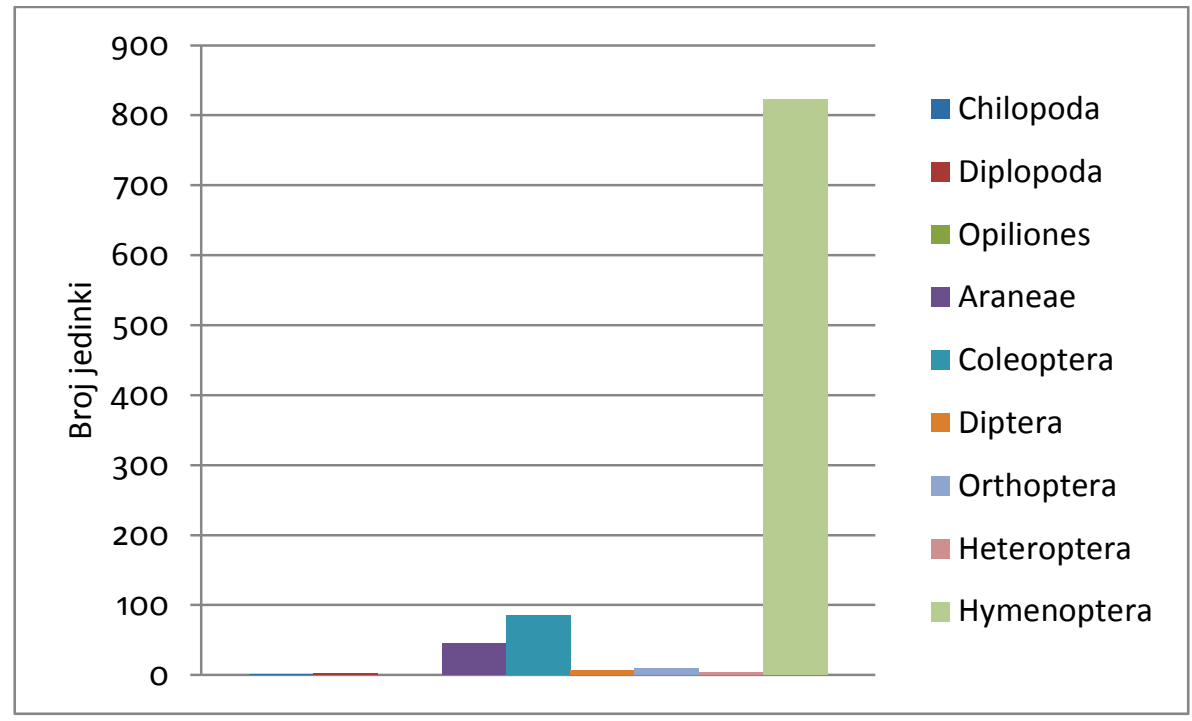

Slika 2. Broj jedinki člankonožaca u zakorovljenom dijelu voćnjaka

Figure 2 Number of arthropod specimens in weedy part of the orchard 
K. Franin i sur.: Fauna prizemnih člankonožaca (Arthropoda) u nasadu smokve (Ficus carica $\mathrm{L}$.)

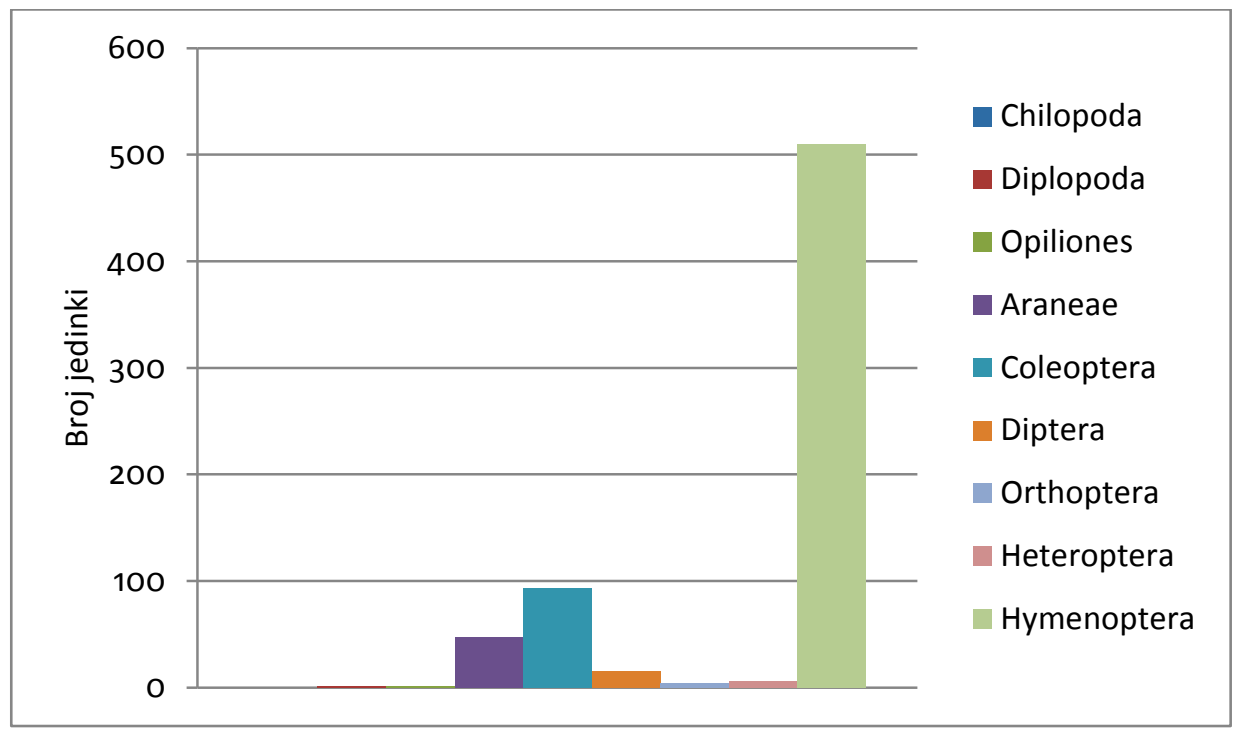

Slika 3. Broj jedinki člankonožaca u pokošenom (malčiranom) dijelu voćnjaka

Figure 3. Number of arthropod specimens in mowed (mulched) part of the orchard

S obzirom na hranidbene navike predstavnike striga (Chilopoda) ubrajamo $\mathrm{u}$ predatore, dok dvojenoge (Diplopoda) mogu biti i fitofagne premda se primarno hrane raspadnutim materijalom biljnog i životinjskog podrijetla (saprofagi). Pauci (Aranea) su također predatori, a lažipauci (Opiliones) se osim plijenom hrane biljnim materijalom, gljivama ali i raspadnutom organskom tvari. Tako Hvam i Toft (2008) u svom radu spominju lažipauke kao predatore vrste Drosophilla melanogaster Meigen. Od kornjaša (Coleoptera) uglavnom prevladavaju korisni kukci. Među njima su kao predatori najznačajniji trčci i kusokrilci (Gotlin Čuljak i Juran, 2016.). Listorošci (Scarabeidae) koji su zastupljeni sa 72 jedinke s obzirom na način ishrane mogu biti fitofagni i saprofagni. Od ostalih saprofagnih kukaca pronađeno je nekoliko jedinki iz porodice Silphidae. Od fitofaga zastupljene su; stjenice (Heteroptera), dvokrilci (Diptera) i ravnokrilci (Orthoptera). S obzirom da fauna člankonožaca nije bila determinirana do vrste nije bilo moguće precizno odrediti brojčani odnos fitofaga, zoofaga i saprofaga. Međutim prema brojnosti dominantnih skupina koje su navedene u prethodnom tekstu možemo zaključiti da 52 jedinke pripadaju isključivim fitofagima, 194 jedinki pripadaju predatorima, a sve ostale bismo mogli ubrojiti u neutralnu skupinu jer ne uzrokuju štete na smokvi. 
K. Franin i sur.: Fauna prizemnih člankonožaca (Arthropoda) u nasadu smokve (Ficus carica L.)

U neutralnu skupinu ubrajamo prvenstveno mrave i saprofitne vrste. Najbrojniji su: opnokrilci (Hymenoptera), kornjaši (Coleoptera) i pauci (Araneae), dok je uhvaćeno svega nekoliko jedinki iz razreda Chilopoda i reda Opiliones (Slika 1.). Najveći broj prikupljenih jedinki pripada porodici Formicidae, te čini 77. $68 \%$ od ukupne faune. U zakorovljenom dijelu je ulovljeno 816, dok je u pokošenom i malčiranom ulovljeno 496 jedinki mrava. Nakon opnokrilaca po ukupnoj brojnosti slijede kornjaši sa sveukupno 204 jedinke, raspoređenih unutar osam porodica. Najbrojnija porodica su trčci (Carabidae) sa sveukupno 70 jedinki. Iako nema podataka o utjecaju trčaka na štetnike smokve Monzó i sur. (2011.) spominju vrstu Pseudophonus rufipes (De Geer) kao mogući biološki agens u suzbijanju mediteranske voćne muhe koja očito postaje sve veći problem u nasadima smokve. Od ostalih člankonožaca zastupljeni su pauci sa sveukupno 92 jedinke. Pronađeno je i nekoliko jedinki stjenica, te 14 ravnokrilaca podijeljenih u tri porodice. Nait Kaci i sur. (2014.) u svom istraživanju navode opnokrilce, pauke i kornjaše kao dominantne redove člankonožaca u nasadu smokve. Merlim i sur. (2005.) navode mrave kao najzastupljeniju skupinu kukaca u fauni smokve, što se podudara sa rezultatima ovog istraživanja. Osim mrava u nešto većem broju pronađeni su i kornjaši, te pauci. Slične rezultate donose Gkisakis i sur. (2014.) u čijem istraživanju također dominiraju kornjaši, te mravi i pauci. Ovim istraživanjem nije uočena zjačajnija razlika u sastavu faune člankonožaca između zakorovljene i pokošene (malčirane) površine voćnjaka. Iako prema većini dosadašnjih istraživanja zatravljeni nasadi smanjuju brojnost fitofagnih organizama, neki autori nisu uočili prednost zatravljenih u odnosu na obrađivane površine (Paredes i sur., 2013.). Mravi nisu tipični štetnici poljoprivrednih kultura, a većina vrsta ne ubraja se ni u prirodne neprijatelje (Maceljski, 2002.). Iako ih je većina polifagna određene vrste su prepoznate kao važni predatori nekih poljoprivrednih štetnika (Offenberg, 2015.). Međutim, u fauni smokve mravi mogu biti potencijalno opasni zbog kukaca koji izlučuju mednu rosu, a koja mravima služi za ishranu ličinki. Choate i Drummond (2011.) u svom radu navode mrave kao korisnu faunu unutar agroekosustava jer se hrane velikim brojem različitih štetnih vrsta ili ih ometaju u ishrani i ovipoziciji, te povećavaju i poboljšavaju kvalitetu tla. Zanimljivo je da je korisna fauna (pauci, trčci i kusokrilci) u gotovo podjednakom omjeru pronađena i na zakorovljenom i na pokošenom dijelu nasada što ide u prilog važnosti vegetacijskog pokrivača kao elementa ekološke infrastrukture koji ovim organizmima osigurava odgovarajuće stanište. S obzirom na prethodno navedene rezultate, vjerojatno uvjeti koje pruža korovom obrastao kao i pokošen te malčiran nasad omogućuju 
K. Franin i sur.: Fauna prizemnih člankonožaca (Arthropoda) u nasadu smokve (Ficus carica $\mathrm{L}$.)

zadovoljavajuće uvjete za nesmetanu aktivnost i funkcioniranje faune prizemnih člankonožaca. U radu su prikazani podaci jednogodišnjeg istraživanja, te je dobiven općeniti prikaz faune člankonožaca. Ovaj rad ima izvjesni značaj u poznavanju faune prizemnih člankonožaca u nasadu smokve na području Ravnih kotara. Međutim, da bismo dobili potpuniji prikaz faune koja obitava u nasadu smokve ovakva istraživanja bi trebalo nastaviti tijekom višegodišnjeg razdoblja, te u svakom slučaju obuhvatiti veće površine.

\section{LITERATURA}

ALONSo-Mũnoz, A., garcia Marí, F. (2011.): Proximity to fig trees increases medfly populations in Citrus orchards. IOBC-WPRS Bulletin. 62: 229-233.

BAIN, A., TZENG, H.T., WU, W.J., CHOU, L.S. (2015.): Ficus (Moraceae) and fig wasps (Hymenoptera: Chalcodoidea) in Taiwan. Botanical studies. 56: $1-12$.

BAKARIĆ, P., BRZICA, K., OMČIKUS, Č. (1989.): Smokva. Stanica za južne kulture, Dubrovnik.

BULIĆ, P., BOHM, D., GAKIĆ, S., MARUŠIĆ, I., POPOVIĆ, L., OSTOJIĆ, I., BJELIŠ, M. (2012.): Mediteranska voćna muha (Ceratitis capitata Wied.) - istraživanje nekih elemenata biološkog ciklusa. U: : Zbornik sažetaka 9. Simpozij o zaštiti bilja u Bosni i Hercegovini, pp. 69-70.

CHOATE, B., DRUMMOND, F. (2011.): Ants as biological control agents in agricultural cropping systems. Terrestial Arthropod Reviews. 4: 157-180.

GKISAKIS, V.D., KOLLAROS, D., KABOURAKIS, E.M. (2014.): Soil arthopod biodiversity in plain and hilly olive orchard agroecosystem, in Crete, Greece. Entomologia Hellenica. 23: 18-28.

GONÇALVES, M.A. (2017.): Mass trapping for the control of the Mediterranean fruit fly Ceratitis capitata (Diptera: Tephritidae) on fig trees in Southern Portugal (Algarve). Acta Horticulturae. 1173: 269-272.

GOTLIN ČULJAK, T., JURAN, I. (2016.): Poljoprivredna entomologija Sistematika kukaca, Sveučilište u Zagrebu, Agronomski fakultet.

HVMAN, A., TOFT, S. (2008.): Prey Preference and Consumption by Some Non-Specialist Harvestman Species (Arachnida: Opiliones). Arachnology 14: 198-205. 
K. Franin i sur.: Fauna prizemnih člankonožaca (Arthropoda) u nasadu smokve (Ficus carica L.)

MACELJSKI, M. (2002.): Poljoprivredna entomologija, Zrinski, Čakovec.

MERLIM, A., GUERRA, J., JUNQUEIRA, R., AQUINO, A. (2005.): Soil macrofauna in cover crops figs grown under organic manadement. Scientia Agricola. 62(1): 57-61.

MIFSUD, D., FALZON, A., MALUMPHY, C., LILLO, E.,VOVLAS, N., PORCELLI, F. (2012.): On some arthropods associated with Ficus species (Moraceae) in the Maltese Islands. Bulletin of the entomological society of Malta. 5: 5-34.

MONZÓ, C., SABATER-MUÑOZ, B., URBANEJA, A., CASTAÑERA, P. (2011.): The ground beetle Pseudophonus rufipes revealed as predator of Ceratitis capitata in citrus orchards. Biological Control. 56: 17-21.

NAIT-KACI, M.B., HEDDE, M., MOUAS BOURBIA, S., DERRIDJ, A. (2014.): Hierarchization of factors driving soil macrofauna in North Algeria groves. Biotechnology Agronomy Society and Enviroment. 18(1): 11-18.

OFFENBERG, J. (2015.): Ants as tools in sustainable agriculture. Journal of Applied Ecology. 52: 1197-1205.

PAREDES, D., CAYUELA, L., GURR, G.M., CAMPOS, M. (2013.): Effect of non-crop vegetation types on conservation biological control of pests in olive groves. PeerJ. 1:e, DOI: 10.7717/peerj.116

PENZAR, I., PENZAR, B. (1989.): Agroklimatologija, Školska knjiga, Zagreb.

PRGOMET, Ž. (2003.): Smokva, SKINK, Rovinj.

SCHMIDT, L. (1970.): Tablice za determinaciju insekata. Sveučilište u Zagrebu, Zagreb.

SINGH, S., KAUR, G. (2017.): Biodiversity of insects and mites pests infesting fig in the Indian Punjab. Acta Horticulturae. 1173: 257-262.

\section{Adresa autora - Authors address:}

Kristijan Franin, e-mail: kfranin@unizd.hr

Matej Ražnjević, Šime Marcelić, Branka Maričić, Tomislav Kos

Sveučilište u Zadru, odjel za ekologiju, agronomiju i akvakulturu Mihovila Pavlinovića 1, 23000 Zadar 